Trabajos y Comunicaciones, 2da. Época, Nº 45, e037, marzo 2017. ISSN 2346-8971

Universidad Nacional de La Plata.

Facultad de Humanidades y Ciencias de la Educación.

Departamento de Historia

\title{
Daniel Moyano (2015). Desde la empresa. Firmas familiares y estructura empresarial en la industria azucarera tucumana, 1895-1930, Buenos Aires: Prometeo libros
}

\author{
Mónica Ochoa * \\ * Universidad Nacional del Noroeste de la Provincia de Buenos Aires, Argentina | \\ ochoa_monica06@hotmail.com
}

El libro es una síntesis de la tesis doctoral de Daniel Moyano, ganadora del IV Concurso de la “Asociación Argentina de Historia Económica” a la mejor Tesis doctoral en Historia Económica. Este trabajo tan bien logrado, es resultado de una investigación realizada entre los años 2006 y 2011.

Es un significativo trabajo que logra un análisis profundo y pormenorizado de los actores de la industria azucarera, en cuanto a sus prácticas y/o estrategias empresariales para alcanzar una buena “performance”. La reducción de la escala de observación ha posibilitado esta tarea, que también aporta un examen generalizador de la cuestión, ya que permite crear una mirada "aproximada” del desenvolvimiento del sector empresarial de la agroindustria.

Varias fueron los interrogantes que guiaron su investigación, a saber: ¿Cómo estaba estructurada la clase empresarial en el Tucumán de entre siglos? ¿Las estrategias de las empresas familiares fueron el secreto de su efectivo funcionamiento?

Para responderlos Moyano ingreso en los registros de tres empresas azucareras tucumanas, realizando un trabajo muy exhaustivo de archivo y un buen análisis de los mismos, lo que posibilito, sin dejar de lado un marco teórico indispensable para este tipo de tarea, una visión alternativa y -por qué no- suplementaria de los trabajos en el área de las industrias agrícolas de Tucumán durante el 
siglo XIX desde el interior de las empresas.

Mucho se ha escrito sobre la industria agroindustrial en la región, cuestión que el autor ratifica al citar a los señeros trabajos de autores tales como María Bravo, Daniel Campi, María Barbero, Fernando Rocchi, Noemí Girbal-Blacha, o José Sánchez Román, sólo por mencionar algunos. Sin embargo, Moyano plantea una visión más micro con respecto a las prácticas empresariales de las burguesías tucumanas que las identifican, y por que no justifican sus decisiones.

Este libro, tal como manifiesta el autor, intenta llenar vacíos historiográficos en torno a la conducta del empresariado azucarero tucumano, a través del análisis de tres empresas. Esto permite lograr un enfoque más específico, en cuanto a las gestiones de los actores sociales que ponen en práctica varias maniobras alternativas para salvar sus empresas en momentos críticos, y poder así elaborar una propuesta más generalizadora con respecto al comportamiento del sector empresarial azucarero tucumano.

El estudio detallado de las fuentes primarias y el análisis de las mismas, ha permitido observar con detalle el desenvolvimiento de las empresas con razones sociales diferentes y con escalas de producción variable. Las firmas examinadas fueron “Avellaneda \& Terán”, la “Compañía Azucarera Juan Manuel Terán”, y la “Compañía Azucarera Santa Lucía”.

El tratamiento a estas fuentes privadas le permitió al autor, abrir canales que explican los procesos que asumieron las empresas en su conjunto. La información contable es claro ejemplo de ello, dado que le permitieron observar la "performance” de las compañías, su rentabilidad y sus inversiones.

Moyano ha utilizado una importante metodología de trabajo, consistente en desglosar la información que aportan las diferentes fuentes -primarias o secundarias- para luego ponerlas en dialogo, confrontarlas y, finalmente elaborar conclusiones generales sobre el comportamiento empresarial. Sus cuadros muestran este trabajo de desglose, comparación y análisis.

La información que acreditan los registros notariales, las sucesiones, los testamentos, las reconversiones de las firmas, los balances anuales, actas de asambleas, etc., le posibilitaron observar el comportamiento del sector empresarial en diferentes situaciones. Pudo así cotejar algunas tendencias compartidas por las empresas, tales como la necesidad por parte de los fundadores de las compañías de procurar que los puestos directivos siempre estuvieran en manos de la familia, y así tener un buen peso en la toma de las decisiones.

El libro esta organizado en cinco capítulos.

El primero de ellos comienza con un relato sobre el recorrido que hace la industria del azúcar para instalarse mayoritariamente en Tucumán, contando para ello con políticas estatales que hicieron posible su desarrollo. El ferrocarril y las medidas proteccionistas fueron algunas ellas. Esas condiciones generaron el denominado “despegue azucarero", caracterizado por una profunda transformación y modernización del sector. (Moyano, p. 31)

Esta situación se ve reflejada en la estructura empresarial que se fue conformando y en los vínculos socio/políticos que estos sectores poseían. El autor, analiza dos periodos económicos (1876-85 y 1885- 95) por los que transita la industria azucarera y señala en ellos los contextos que la optimizaron y las que no tanto, así como también las diferentes formas societarias que se generaron 
para lograr el control de la propiedad y de las sociedades. Para ello incorpora al estudio, la empresa familiar "Avellaneda \& Terán”, que junto a otras, constituyeron el denominado "capitalismo familiar azucarero" tucumano (p. 57)

En el segundo capitulo se trabaja con los efectos que provoco la crisis de sobreproducción y las acciones que llevaron adelante los industriales para amortizar lo mas posible los efectos de la caída del precio del azúcar.

En su análisis, Moyano, recorre el escenario jurídico que se conforma para regular la producción (leyes machetes), y las consecuencias que esta situación motiva, como por ejemplo, la redefinición de las políticas crediticias mas duras que obligaron a muchas empresas a recurrir a otras maneras "no formales" (p.64) de financiamiento, para costear los gastos de producción, y/o hacer frente a las deudas ocasionadas por la presión impositiva y el encarecimiento de los prestamos.

El fracaso de los acuerdos entre productores acentuaron las fisuras entre ellos y nuevamente una sobreproducción repercutió en el estado financiero de las empresas. La confrontación de datos entre las diferentes industrias del azúcar le permite al autor analizar las estrategias utilizadas para superar las crisis, como así también los cambios que se produjeron en la estructura empresarial entre 1895 y 1914.

Estos cambios los va a observar en el tercer capítulo denominado "del abarrotamiento del mercado a la escasez del producto 1906-1915 “. En este segmento el autor realiza una indagación causada por una cuestión que observó en el tratamiento de las fuentes testamentarias: los motivos que asumieron algunas empresas para optar por el formato de S.A. y otras permanecieron como sociedades solidarias. Para responder este interrogante, el autor amplia la lente de observación e incorpora a otro ingenio, el de Santa Bárbara, y examina así la conformación de un "núcleo empresarial” tucumano, que va a actuar hasta finales del periodo estudiado.

En el cuarto capitulo, Moyano, estudia las consecuencias que sufrieron las empresas, generadas por la crisis "biológica” (la plaga del mosaico) y las estrategias utilizadas para sortearlas. Desde el replante de la caña de Java a la utilización de reservas y financiamiento interno con interés bancario, como así también la utilización de préstamos personales a corto plazo que permitieron lograr la estabilidad.

En el último capitulo, el autor trabaja analizando la capacidad de las empresas para aumentar y perfeccionar su producción, reduciendo costos y mejorando la calidad de los azucares. Esto trajo como consecuencia la sobreoferta y el desequilibrio en los precios durante la década de 1920.

Aunque el problema mas acuciante, lo represento el conflicto entre el sector empresarial y cañeros, que se manifestó en la convocatoria a una huelga cuyo arbitraje lo llevo a cabo el gobierno nacional. Por entonces se creó un mecanismo de control y regulación de los precios de la caña (Moyano, p. 158).

En un segundo apartado del capitulo, el autor trabaja en las transformaciones que las empresas azucareras debieron afrontar, como por ejemplo, el ingreso a las tradicionales compañías, de terceros en los equipos directivos, aunque con una mínima participación. Muestra el autor, la reconversión de las empresas asociándose a nuevas actividades, diversificando sus funciones, pero 
manteniendo ese control del "capital familia tucumana” por medio de las redes sociales o las alianzas, que provocaban un asocianismo empresarial.

Este libro constituye un significativo aporte a la historia de las empresas familiares, con una gran recolección de fuentes y una metodología impecable en el tratamiento de las mismas. En este proceso se entrelazan el análisis y una gran contribución para aquellos que se dedican al estudio de las empresas familiares.

Iniciativas como la de este libro son necesarias y muy beneficiosas para que se continúe con la labor de complementarlas, y poder así contar con una mayor cantidad de material de consulta sobre estas problemáticas.

Esta publicación mira desde otra perspectiva -una más reducida- a las citadas firmas, lo cual le permite vincular los resultados económicos, con la formación de un sólido sector empresarial y explicar, por medio de la comparación, la continuidad de las familias en las direcciones de sus respectivas compañías. De alguna manera, su metodología de trabajo en cuanto al tratamiento de las fuentes, es un modelo a seguir para aquellos que realizamos investigaciones sobre empresas familiares. Al mismo tiempo, es una lectura recomendable para aquellos investigadores que incursionan en la gran tarea de "explorar" la historia del conjunto de empresas y empresarios de la argentina. 